\title{
Can Immune Thrombocytopenia Be Cured with Medical Therapy?
}

\author{
Adam Cuker, MD, MS ${ }^{1,2}$ Eline T. Luning Prak, MD, $\mathrm{PhD}^{2}$ Douglas B. Cines, $\mathrm{MD}^{1,2}$ \\ ${ }^{1}$ Department of Medicine, Perelman School of Medicine, University of \\ Pennsylvania, Philadelphia, Pennsylvania \\ 2 Department of Pathology and Laboratory Medicine, Perelman School \\ of Medicine, University of Pennsylvania, Philadelphia, Pennsylvania \\ Address for correspondence Adam Cuker, MD, MS, Hospital of the \\ University of Pennsylvania, 3400 Spruce Street, Philadelphia, PA 19027 \\ (e-mail: adam.cuker@uphs.upenn.edu).
}

Semin Thromb Hemost 2015;41:395-404.

\begin{abstract}
Keywords

- immune thrombocytopenia

- treatment

- cure

- remission
\end{abstract}

Immune thrombocytopenia (ITP) is an autoimmune disorder characterized by antibody- and cell-mediated platelet destruction and impairment of platelet production. Patients experience an increased risk of bleeding and reduced quality of life. ${ }^{1}$ ITP may occur in isolation (primary ITP) or in association with a predisposing etiology (secondary ITP). ${ }^{2}$

Some presentations of ITP are associated with a favorable prognosis. Childhood ITP frequently follows a viral infection and is self-limited in approximately $80 \%$ of cases. ${ }^{3}$ ITP secondary to human immunodeficiency virus generally resolves with microbial suppression. ${ }^{4}$

Primary ITP of adulthood, in contrast, follows a chronic course in a majority of cases. A major goal of treatment in this population is attainment of durable improvement in the platelet count without the need for ongoing therapy. Splenectomy has long been the surest means of accomplishing this objective.
Two-thirds of patients have normalization of the platelet count after splenectomy and an additional $22 \%$ evidence a partial response. $^{5}$ The benefits of splenectomy must be weighed against potential harms including risks associated with anesthesia and the surgery itself, a life-long increased risk of sepsis, and an elevated incidence of late vascular complications. ${ }^{6}$

In light of these concerns, patients and clinicians are increasingly inclined toward medical therapy. ${ }^{7}$ Unlike splenectomy, however, conventional medical therapy (e.g., prednis(ol)one, intravenous immunoglobulin [IVIG], thrombopoietin receptor agonists [TPO-RAs]), with the possible exception of rituximab, is generally viewed as a means of achieving a transient platelet count response with little or no potential to induce long-term remission off therapy. Recent studies have tested the hypothesis that intensive medical therapy, particularly early in the disease course, may ameliorate the long-term course or even cure ITP. In
Issue Theme Hot Topics VII; Guest Editor: Emmanuel J. Favaloro, PhD, FFSc (RCPA).
Copyright $\odot 2015$ by Thieme Medical Publishers, Inc., 333 Seventh Avenue, New York, NY 10001, USA. Tel: +1(212) 584-4662.
DOI http://dx.doi.org/ 10.1055/s-0034-1544001. ISSN 0094-6176. 
this review, we discuss the biological rationale for early aggressive medical intervention and critically analyze data on longterm outcomes in adults with primary ITP treated with medical therapy.

\section{Biological Rationale for Early Intensive Medical Therapy}

Whether or not an ITP patient responds to initial therapy will depend, in part, on the immunologic perturbations that gave rise to the disease. We propose that there are two main immunologic drivers of chronic ITP. One is the adaptive immune response (B and $\mathrm{T}$ cells), and the other is the inflammatory milieu (exogenous antigens, complement, inflammatory cytokines, autoantigens, and platelet injury). In patients with combined adaptive and inflammatory immunologic defects, targeting only the B cells may be ineffective because the underlying inflammatory environment has not changed. Similarly, targeting only inflammation may not abrogate pathogenic B or T cells. Hence, the use of potent combination therapies that target both inflammation (such as high-dose dexamethasone) and B cells (such as rituximab) may be more effective in halting an autoimmune response than either therapy alone., 8

In addition to the kind (and complexity) of the immunologic disturbance influencing disease outcome, we propose that the longevity of the immune response is important. Of course, this is a circular argument: a good predictor of chronicity in any autoimmune disease is chronicity itself. In a long-term analysis of 69 adult ITP cases, 2 out of 19 patients with a history of ITP for more than 6 months had sustained increases in their platelet counts following corticosteroid therapy, whereas 28 out of 50 patients with a history of ITP for less than 6 months had sustained responses. ${ }^{10}$ Similar findings have been obtained in other series. ${ }^{11,12}$ It is worth understanding why.

Fundamentally, the initial disease may be driven by a primary immune response, whereas chronic disease may reflect a memory response. There are several potential reasons why it may be easier to eliminate a primary immune response than a memory response (-Fig. 1). The comments that follow are focused mainly on B cells, but they can be extended to T cells as well.

\section{Clonal Expansion: It Is a Number Game}

By allowing autoimmunity to persist without reduction of inflammation or other immune-activating signals, autoreactive B cell clones may increase in abundance and therefore become more difficult to eliminate. ${ }^{13}$ For example, suppose that a hypothetical therapy eliminates $99 \%$ of mature B cells and that a pathogenic clone needs to have at least 100 members to survive and persist. If the clone is permitted to expand to more than 10,000 members, it could be more likely to survive treatment and induce relapse. Conversely, treatment could, in theory, produce a cure if it is administered early in the course of disease, while the pathogenic clones are still relatively small.

\section{Affinity Maturation: The Quality of the Immune Response Matters}

With an ongoing autoimmune response, pathogenic B cell clones undergo diversification of their antigen receptors via somatic hypermutation. Positive selection for platelet-autoantigen binding likely results in antibodies with higher affinities for platelets over time. Higher affinity antibodies, in turn, may be able to exert more potent effects at lower concentrations. Chronic immune stimulation can also result in increased titers of autoantibodies. In light of these considerations, it is not entirely surprising that ITP patients who have antiplatelet antibodies at diagnosis are more likely to have persistent thrombocytopenia at 1 year. ${ }^{14}$

\section{Epitope Spreading: The Diversity of the Autoimmune Response Can Serve as a Feed-Forward Loop}

An ongoing immune response can be amplified by epitope spreading. ${ }^{15,16}$ Over time, T cell clones having specificities for different epitopes in platelet autoantigens may be recruited into long-lived germinal centers or extrafollicular foci. While the number of distinct antibody heavy and light chain pairings that comprise antiplatelet antibodies in ITP appears to be limited, somatic hypermutation may broaden the antiplatelet antibody response. ${ }^{17,18}$ Members of autoreactive $B$ cell clones with different somatic mutations may result in varying specificities. These varied specificities may facilitate the activation of pathogenic cells (e.g., more diverse B cell clones may be able to help a larger diversity of T cells and vice versa), resulting in a feed-forward loop of B-T collaboration that serves to amplify and sustain the autoimmune response. ${ }^{19}$

A larger diversity of antibodies that bind to different epitopes on the same platelet may increase the number or configuration of antibodies that decorate the platelet and promote more efficient opsonization, phagocytosis, or interfere with platelet function or generation. ${ }^{20}$ Antibodies with different specificities may exert additive pathophysiologic effects. For example, some antibodies directed against glycoprotein Ib impair thrombopoiesis. ${ }^{21}$ Early and aggressive therapy before the autoimmune response is allowed to broaden may enhance the likelihood of durable response or cure.

\section{Functional Diversification of Autoantibody Effector Functions}

Isotype switching of antibodies during the course of an immune response can result in more potent immunologic effector functions (which are encoded by the constant regions of the antibody). This, in turn, can result in antibodies that differ in their ability to activate complement and in B cells that have different thresholds of activation ${ }^{22}$ and FcR interactions with phagocytic cells, enhancing platelet clearance. Furthermore, altered signaling dynamics can occur with different antibody constant regions. ${ }^{23,24}$

\section{Generation of Long-Lived Memory Populations that Differ from Primary B Cells}

Chronic immune responses may generate specialized effector and memory cell populations, such as long-lived plasma cells, that may not have been produced as efficiently (or at all) if the disease had been promptly and definitively treated. Some of these populations may be challenging to eradicate because they may reside in protective niches and have increased 


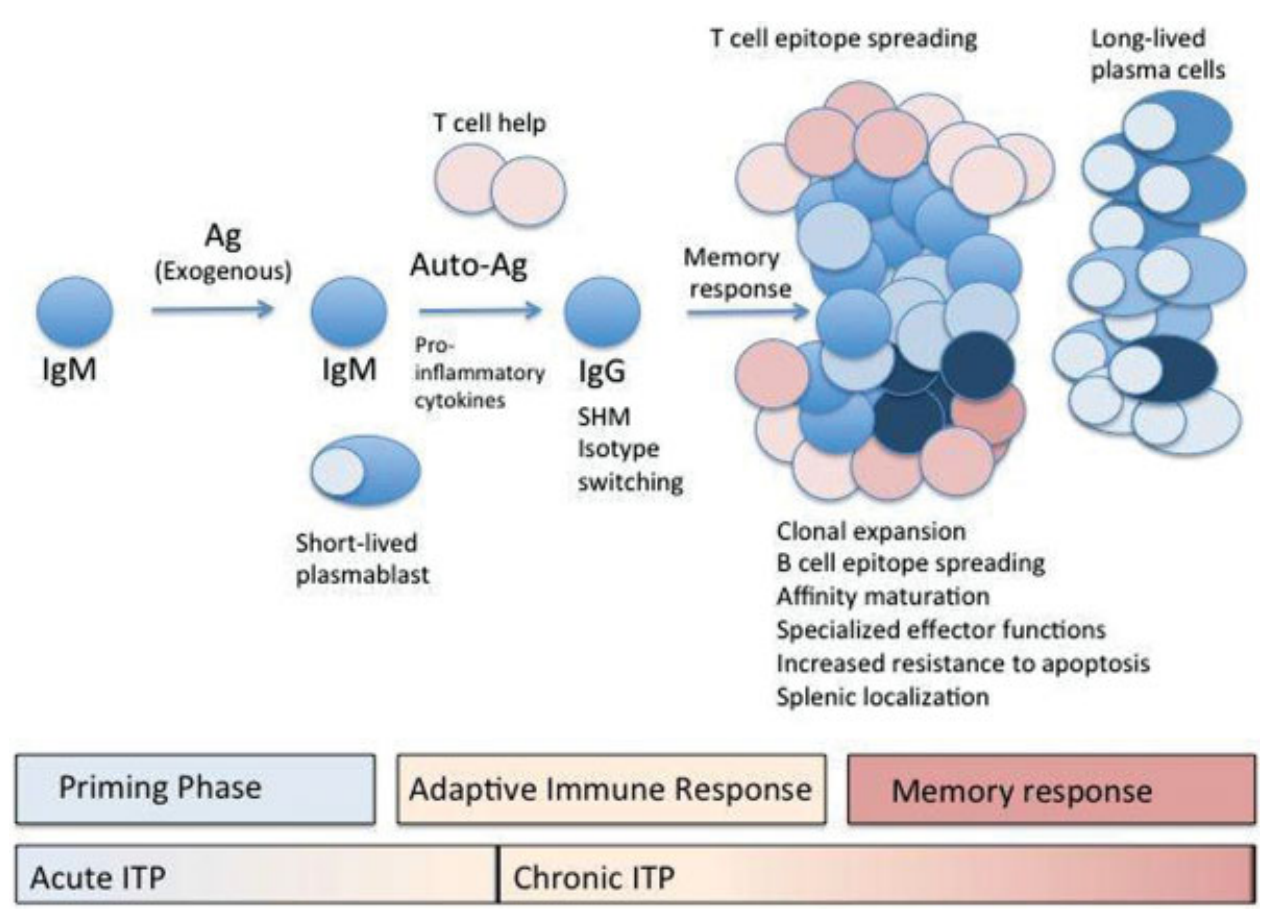

Fig. 1 The generation of immunologic memory and persistence of ITP. A schematic of how the immune response may evolve over time in patients with ITP. We propose that most, if not all, patients with ITP initially respond to some type of exogenous antigen. During this initial priming phase, lasting 2-4 weeks, short-lived plasmablasts secrete antibodies and some of the antibodies that are produced happen to bind not only to the exogenous antigen but also to platelets. In many individuals, the priming phase ends and platelet counts increase without the need for further therapy as antigen is cleared. However, in some individuals, additional factors such as chronic inflammation, defective self-tolerance, or persistent antigenemia drive the adaptive immune response and over time this response evolves into a full-fledged memory response, with successive cycles of clonal expansion, somatic hypermutation, selection for high-affinity antibodies, and progressive diversification of responding antigen and $T$ cell receptor repertoires (epitope spreading). The memory response is harder to eliminate than the primary response, because the number and diversity of responding clones is increased. Furthermore, the anatomic localization of the responding cells, their potentially lower threshold for activation, and increased resistance to apoptosis may make them harder to eliminate. These differences between primary and memory immune responses provide a biological rationale for the use of early and aggressive treatments that rapidly abrogate the priming immune response in the setting of initial disease before the memory response has a chance to become established. Ag, antigen; ITP, immune thrombocytopenia; SHM, somatic hypermutation. Different shades of the same color indicate different antibody (blue) or T cell receptor (red) clonotypes.

resistance to apoptotic death. ${ }^{25}$ For example, short-lived antibody forming cells express low levels of CD20 and are eliminated with anti-CD20 therapy (which also removes the precursor pools, as evidenced by the rapid and robust loss of IgM responses in rituximab-treated patients who receive vaccines ${ }^{26}$ ), but long-lived CD20-negative plasma cells could take months or years to turn over, even if CD20+ precursor populations are eliminated. ${ }^{27}$ Memory B cells can also have lower activation thresholds than primary B cells. For example, they can rapidly upregulate the co-stimulatory molecules CD80 and CD86. ${ }^{28}$ Memory cells can rapidly differentiate into antibody-secreting cells after CD40 ligation and costimulation with cytokines, unlike naive B cells. ${ }^{29}$ Memory cells also undergo enhanced proliferation in response to B cell receptor signaling. ${ }^{30}$ Finally, the anatomic localization of memory cells may play an important role in ITP pathogenesis. The spleen, which is an important organ for clearance of platelets, contains a much higher frequency of memory $B$ cells than the peripheral blood, potentially putting immune effectors into more intimate contact with their targets. ${ }^{31}$

The relevance of the aforementioned changes in the autoimmune response over time, as it progresses from a primary to a memory response, to the prognosis of ITP and its responsiveness to therapy requires further investigation because at present there is no way to monitor pathogenic $B$ or $\mathrm{T}$ cell populations in vivo. Nevertheless, there is a biological rationale for clinical trials of intensive medical therapy that targets both innate and adaptive arms of the immune system early in ITP to ameliorate its long-term course.

\section{Natural History and Standard First-Line Therapy}

Assessment of the potential for therapies to improve longterm outcomes in ITP requires an understanding of the natural history of the disease and rates of spontaneous remission. However, prospective studies of untreated ITP in adults with moderate to severe thrombocytopenia (platelet count $<50 \times 10^{9} / \mathrm{L}$ ) have not been performed. In the absence of such data, randomized controlled trials of standard firstline therapy (e.g., standard-dose corticosteroids, IVIG, anti-D) in newly diagnosed adults provide a baseline against which the impact of other treatments on long-term outcomes may be compared (-Table $\mathbf{1}$ ).

In a multicenter Italian study, 69 adults were randomized to prednisone 0.5 or $1.5 \mathrm{mg} / \mathrm{kg} / \mathrm{day}$ for up to $1 \mathrm{month}$. The rate 
Table 1 Platelet count responses at 6-12 months in randomized controlled trials of standard first-line therapy in adults with recently diagnosed ITP

\begin{tabular}{|c|c|c|c|c|}
\hline \multirow[t]{2}{*}{ References } & \multirow[t]{2}{*}{ Intervention } & \multirow{2}{*}{$\begin{array}{l}\text { Definition of platelet } \\
\text { response }\end{array}$} & \multicolumn{2}{|c|}{ Response rate } \\
\hline & & & $6 \mathrm{mo}$ & $12 \mathrm{mo}$ \\
\hline 32 & $\begin{array}{l}\text { Prednisone } 0.5 \mathrm{mg} / \mathrm{kg} / \mathrm{d} \times \leq 1 \mathrm{mo} \\
\text { Prednisone } 1.5 \mathrm{mg} / \mathrm{kg} / \mathrm{d} \times \leq 1 \mathrm{mo}\end{array}$ & $\geq 60 \times 10^{9} / \mathrm{L}$ & $\begin{array}{l}65 \% \\
66 \% \\
\end{array}$ & - \\
\hline 33 & $\begin{array}{l}\text { Prednisone } 0.25 \mathrm{mg} / \mathrm{kg} / \mathrm{d} \times 3 \mathrm{wk} \\
\text { Prednisone } 1 \mathrm{mg} / \mathrm{kg} / \mathrm{d} \times 3 \mathrm{wk}\end{array}$ & $\geq 50 \times 10^{9} / \mathrm{L}$ & $\begin{array}{l}60 \% \\
58 \%\end{array}$ & - \\
\hline 34 & $\begin{array}{l}\text { Methylprednisolone } 15 \mathrm{mg} / \mathrm{kg} / \mathrm{d} \times 3 \mathrm{~d}^{\mathrm{a}} \\
\text { IVIG } 0.7 \mathrm{~g} / \mathrm{kg} / \mathrm{d} \times 3 \mathrm{~d}^{\mathrm{a}}\end{array}$ & $>50 \times 10^{9} / \mathrm{L}$ & - & $\begin{array}{l}40 \% \\
36 \% \\
\end{array}$ \\
\hline 35,36 & $\begin{array}{l}\text { Anti-D } 50 \mu \mathrm{g} / \mathrm{kg} \text { initial infusion }{ }^{\mathrm{b}} \\
\text { Anti-D } 75 \mu \mathrm{g} / \mathrm{kg} \text { initial infusion }\end{array}$ & $>30 \times 10^{9} / \mathrm{L}$ & $43 \%^{c}$ & - \\
\hline
\end{tabular}

Abbreviations: ITP, immune thrombocytopenia; IVIG, intravenous immunoglobulin.

${ }^{a}$ Followed by a second randomization to prednisone $1 \mathrm{mg} / \mathrm{kg} /$ day or placebo on days 4-21.

${ }^{b}$ Infusions were repeated whenever the platelet count fell below $30 \times 10^{9} / \mathrm{L}$. Patients were eligible to crossover to the other dose.

${ }^{c} 43 \%$ of patients maintained a platelet response for $\geq 6$ months off treatment. The response rate represents an aggregate for patients in both treatment arms.

of sustained response (platelet count $\geq 60 \times 10^{9} / \mathrm{L}$ ) at 6 months was 65 and $66 \%$, respectively. ${ }^{32}$ Similar results were obtained in a randomized trial $(n=223)$ comparing two different doses of prednis(ol)one ( $0.25 \mathrm{vs} .1 \mathrm{mg} / \mathrm{kg} /$ day $)$ over 3 weeks followed by a rapid taper. Rate of response (platelet count $\geq 50 \times 10^{9} / \mathrm{L}$ and no treatment for at least 3 months) at 6 months was similar in the low- and high-dose groups (60 vs. 58\%). ${ }^{33}$ French investigators randomized 122 newly diagnosed adults to methylprednisolone $15 \mathrm{mg} / \mathrm{kg} /$ day or IVIG $0.7 \mathrm{~g} / \mathrm{kg} /$ day on days 1 to 3 followed by a second randomization to placebo or prednisone $1 \mathrm{mg} / \mathrm{kg} /$ day on days 4 to 21 . Sustained response (platelet count $>50 \times 10^{9} /$ L) at 1 year was equivalent in the methylprednisolone and IVIG arms (40 vs. 36\%). Prednisone significantly delayed the median time to relapse (152 vs. 22.5 days), but did not significantly increase the rate of sustained response at 1 year compared with placebo. ${ }^{34}$ Twenty-eight $\mathrm{Rh}+$, nonsplenectomized adults with ITP diagnosed within the previous 12 months were randomized to an initial anti-D infusion of 50 or $75 \mu \mathrm{g} / \mathrm{kg}$. Infusions were repeated whenever the platelet count fell below $30 \times 10^{9} / \mathrm{L}^{35}$ After a median 11.5 months of therapy, $12(43 \%)$ patients maintained a platelet count greater than $30 \times 10^{9} / \mathrm{L}$ off all treatment for at least 6 months. ${ }^{36}$

Data on outcomes with prednis(ol)one beyond 1 year come from retrospective cohort studies. Long-term platelet response rates range from 8 to $46 \%$ (- Table 2). ${ }^{10,37-41}$ The wide variability observed in these series may reflect differences in patient population, dose and duration of treatment with prednis(ol)one, definitions of platelet response, and duration of follow-up. The bulk of the evidence suggests that approximately a quarter of adults with newly diagnosed ITP enjoy durable responses after treatment with standarddose prednis(ol)one lasting well beyond 1 year.

Taken together, these data indicate that approximately 40 to $60 \%$ of adults with newly diagnosed ITP maintain a response at 6 months after initial treatment with standard first-line therapies ( - Table $\mathbf{1}$ ), but only a small minority

Table 2 Platelet count responses to prednis(ol)one beyond 1 year in adults with ITP

\begin{tabular}{|l|l|l|l|l|l|l|}
\hline Reference & Setting & $\boldsymbol{n}$ & Intervention & $\begin{array}{l}\text { Definition of } \\
\text { platelet response }\end{array}$ & $\begin{array}{l}\text { Response } \\
\text { rate }(\%)\end{array}$ & $\begin{array}{l}\text { Duration of } \\
\text { platelet response }\end{array}$ \\
\hline 37 & United States & 57 & Prednisone $\geq 40 \mathrm{mg} / \mathrm{d} \times \geq 4 \mathrm{wk}$ & $\geq 50 \times 10^{9} / \mathrm{L}$ & 37 & $1-18 \mathrm{y}$ \\
\hline 38 & United States & 59 & Prednisone $^{\mathrm{a}}$ & $\geq 150 \times 10^{9} / \mathrm{L}$ & 22 & $37 \mathrm{mo}^{\mathrm{b}}$ \\
\hline 10 & Italy & 134 & Prednisone $1 \mathrm{mg} / \mathrm{kg} / \mathrm{d} \times 1 \mathrm{mo}$ & $\geq 120 \times 10^{9} / \mathrm{L}$ & 8 & $92 \mathrm{mo}^{\mathrm{b}}$ \\
\hline 39 & The Netherlands & 124 & Prednisone $1 \mathrm{mg} / \mathrm{kg} / \mathrm{d} \times 3-6 \mathrm{wk}$ & $\geq 30 \times 10^{9} / \mathrm{L}$ & 27 & $2 \mathrm{y}$ \\
\hline 40 & China & 54 & Prednisolone $1 \mathrm{mg} / \mathrm{kg} / \mathrm{d}^{\mathrm{c}}$ & $>100 \times 10^{9} / \mathrm{L}$ & 46 & $116 \mathrm{mo}^{\text {d }}$ \\
\hline 41 & Turkey & 129 & Prednisone $1 \mathrm{mg} / \mathrm{kg} / \mathrm{d} \times 2-4 \mathrm{wk}^{\mathrm{e}}$ & $>100 \times 10^{9} / \mathrm{L}$ & 22 & $33 \mathrm{mo}^{\mathrm{b}}$ \\
\hline
\end{tabular}

Abbreviation: ITP, immune thrombocytopenia.

aDose and duration not specified.

${ }^{\mathrm{b}}$ Median.

'Duration not specified.

dMean.

e 14 subjects received high-dose dexamethasone rather than prednisone. 
remains free of relapse beyond 1 year. Most patients experience a chronic or relapsing/remitting course. Rarely, patients with chronic disease may experience seemingly spontaneous improvements in platelet count years after diagnosis. ${ }^{42}$ The immunologic basis for this phenomenon is unknown. In at least some cases, apparent spontaneous remission may actually represent thrombocytopenia due to other causes. For example, in a series of 343 adults with suspected ITP, the diagnosis was subsequently reclassified as drug-induced immune thrombocytopenia in 22 subjects. ${ }^{43}$

\section{Single-Agent Therapy}

\section{High-Dose Dexamethasone}

Dexamethasone has a longer half-life and considerably less mineralocorticoid activity than prednis(ol)one. High-dose dexamethasone is typically administered at a dose of $40 \mathrm{mg}$ (equivalent to prednisone $267 \mathrm{mg}$ ) daily for 4 consecutive days. Repeated cycles may be given every 2 to 4 weeks.

High-dose dexamethasone has been studied in several prospective studies of adults with previously untreated ITP (-Table 3). In a single-arm Chinese study involving 125 subjects, a single cycle of high-dose dexamethasone produced a sustained response (platelet count $>50 \times 10^{9} / \mathrm{L}$ ) in $50 \%$ of patients at 6 months, ${ }^{44}$ a result similar to 6 -month response rates observed in studies of standard-dose prednisone. ${ }^{32,33}$ In a multicenter trial from Korea, 151 patients with treatment-naive ITP were randomized to receive a single cycle of high-dose dexamethasone or prednisolone $1 \mathrm{mg} /$ $\mathrm{kg} /$ day $\times 4$ weeks. Sustained responses (platelet count $>30$ $\times 10^{9} / \mathrm{L}$ ) at 6 months were observed in $25 \%$ of patients in the dexamethasone arm and $36 \%$ in the prednisolone arm $(p=0.33)$. Eight $(11 \%)$ patients in the dexamethasone arm and $17(23 \%)$ in the prednisolone arm had a platelet count $>100 \times 10^{9} / \mathrm{L}$ at 1 year. ${ }^{45}$ These data suggest that a single cycle of high-dose dexamethasone does not improve longterm outcomes compared with standard-dose prednis(ol) one. At variance with these findings, an Iranian randomized controlled trial involving 60 adults with newly diagnosed ITP demonstrated superior rates of response (platelet count $\geq 30$ $\left.\times 10^{9} / \mathrm{L}\right)$ with a single cycle of high-dose dexamethasone (followed by prednisolone $1 \mathrm{mg} / \mathrm{kg} /$ day tapered over 6 weeks) compared with prednisolone $1 \mathrm{mg} / \mathrm{kg} /$ day $\times 4$ weeks at 6 months (90 vs. $53 \%, p<0.0001)$ and 1 year (90 vs. 47\%, $p<0.0001$ ). Use of prednisolone following dexamethasone may explain the very high response rates observed in the high-dose dexamethasone arm relative to other studies. ${ }^{46}$

The effect of multiple cycles of high-dose dexamethasone on long-term response rates in adults with previously untreated ITP has been tested in three single-arm studies (-Table 2). In a small Dutch study, 18 previously untreated patients received high-dose dexamethasone every 28 days for up to 6 cycles. Twelve (67\%) patients maintained a response (platelet count $\geq 50 \times 10^{9} / \mathrm{L}$ ) after a median follow-up of 8.5 months. ${ }^{47}$ In a single-center single-arm study from Italy, 37 previously untreated adults received high-dose dexamethasone every 28 days for 6 cycles. Of 33 patients with a response (platelet count $\geq 20 \times 10^{9} / \mathrm{L}$ ), 8 relapsed after a median of 19.5 months. The remaining 25 patients had a sustained response at the end of the observation period. Among responders, the estimated relapse-free survival was $90 \%$ at 15 months and $58 \%$ at 50 months. ${ }^{48}$ Forty-eight previously untreated adults were treated with high-dose dexamethasone every 14 days for 4 cycles in a multicenter Italian study. The rate of freedom from relapse (platelet count $<30 \times 10^{9}$ / L) was $60 \%$ at 15 months. ${ }^{48}$

Table 3 Platelet count responses at 6-12 months in prospective studies of high-dose dexamethasone given as a single cycle or multiple cycles in adults with previously untreated ITP

\begin{tabular}{|c|c|c|c|c|c|}
\hline \multirow[t]{2}{*}{ Reference } & \multirow[t]{2}{*}{$n$} & \multirow[t]{2}{*}{ Intervention } & \multirow[t]{2}{*}{ Definition of platelet response } & \multicolumn{2}{|c|}{ Response rate } \\
\hline & & & & $6 \mathrm{mo}$ & $12 \mathrm{mo}$ \\
\hline \multicolumn{6}{|c|}{ Single cycle studies } \\
\hline 44 & 125 & Dex $40 \mathrm{mg} / \mathrm{d}$ on days $1-4 \times 1$ cycle & $>50 \times 10^{9} / \mathrm{L}$ & $50 \%$ & - \\
\hline 45 & 151 & $\begin{array}{l}\text { Dex } 40 \mathrm{mg} / \mathrm{d} \text { on days } 1-4 \times 1 \text { cycle } \\
\text { Prednisolone } 1 \mathrm{mg} / \mathrm{kg} / \mathrm{d} \times 4 \mathrm{wk}\end{array}$ & $>30 \times 10^{9} / \mathrm{L}$ & $\begin{array}{l}25 \% \\
36 \%\end{array}$ & $\begin{array}{l}- \\
-\end{array}$ \\
\hline 46 & 60 & $\begin{array}{l}\text { Dex } 40 \mathrm{mg} / \mathrm{d} \text { on days } 1-4 \times 1 \text { cycle and } \\
\text { Prednisolone } 1 \mathrm{mg} / \mathrm{kg} / \mathrm{d} \text { tapered over day } 5-46 \\
\text { Prednisolone } 1 \mathrm{mg} / \mathrm{kg} / \mathrm{d} \times 4 \mathrm{wk}\end{array}$ & $\geq 30 \times 10^{9} / \mathrm{L}$ & $\begin{array}{l}90 \% \\
53 \%\end{array}$ & $\begin{array}{l}90 \% \\
47 \%\end{array}$ \\
\hline \multicolumn{6}{|c|}{ Multiple cycle studies } \\
\hline 47 & 18 & Dex $40 \mathrm{mg} / \mathrm{d}$ on days $1-4$ q28 days $\times \leq 6$ cycles $^{\text {a }}$ & $\geq 50 \times 10^{9} / \mathrm{L}$ & $67 \%$ & - \\
\hline 48 & 37 & Dex $40 \mathrm{mg} / \mathrm{d}$ on days $1-4 \mathrm{q} 28$ days $\times 6$ cycles & $\geq 20 \times 10^{9} / \mathrm{L}$ & - & $68 \%^{\mathrm{c}}$ \\
\hline 48 & 48 & Dex $40 \mathrm{mg} / \mathrm{d}$ on days $1-4$ q14 days $\times 4$ cycles & $\geq 30 \times 10^{9} / \mathrm{L}$ & - & $60 \%^{\mathrm{d}}$ \\
\hline
\end{tabular}

Abbreviations: Dex, dexamethasone; ITP, immune thrombocytopenia.

${ }^{\text {a } T h e ~ d e x a m e t h a s o n e ~ d o s e ~ w a s ~ t a p e r e d ~ b e t w e e n ~ d a y s ~} 5$ and 8 of each cycle.

bAt median 8.5 mo.

'At median 19.5 mo.

${ }^{\mathrm{d}}$ At median 15 mo. 
These data indicate that multiple cycles of high-dose dexamethasone may produce longer-term responses compared with a single cycle of high-dose dexamethasone or standarddose prednis(ol)one. However, comparisons are hampered by lack of a control arm in the studies of multiple cycles of dexamethasone ( - Table 3 ). A randomized controlled trial of prednisone $1 \mathrm{mg} / \mathrm{kg} /$ day $\times 4$ weeks versus high-dose dexamethasone every 14 days for 3 cycles is currently recruiting (ClinicalTrials.gov Identifier NCT00657410). We are unaware of a biologic rationale to explain why high-dose corticosteroids administered in short pulses might be more effective in abrogating the autoimmune response in ITP than standarddose corticosteroids. It may be a simple matter of cumulative glucocorticoid dose. For example, four cycles of high-dose dexamethasone delivers approximately twice the total corticosteroid dose as prednisone $70 \mathrm{mg} /$ day $\times 1$ month. Further investigation is needed to determine whether multicycle highdose dexamethasone exerts fundamentally different effects on the immune system compared with standard-dose prednis(ol) one or merely facilitates delivery of greater cumulative doses of corticosteroids.

\section{Rituximab}

Rituximab is a chimeric monoclonal antibody directed against the B cell surface antigen CD20. The usual dose is $375 \mathrm{mg} / \mathrm{m}^{2}$ weekly $\times 4$ weeks, though other regimens are also effective. ${ }^{49}$

Rituximab has been tested in several small prospective and retrospective cohorts of previously treated patients with ITP. The results of these studies have been summarized in two systematic reviews. One included 19 studies, which collectively enrolled 313 patients (50.5\% splenectomized). A response (platelet count $\geq 50 \times 10^{9} / \mathrm{L}$ ) was observed in $62.5 \%$ of patients. The median duration of response was 10.5 months. ${ }^{50} \mathrm{~A}$ second systematic review was restricted to non-splenectomized patients (19 studies, 368 patients). At 1 year, the sustained response (platelet count $\geq 50 \times 10^{9} / \mathrm{L}$ ) rate was $57 \%{ }^{51}$

Rituximab has been compared with placebo in a single pilot randomized controlled trial. Sixty patients (28 with newly diagnosed ITP) were randomized to receive standard-dose rituximab or placebo infusions. Concomitant therapy (e.g., corticosteroids, IVIG) was permitted for the first 8 weeks. An overall response (platelet count $\geq 30 \times 10^{9} / \mathrm{L}$ and at least a twofold increase from baseline) at 6 months was achieved in $62.5 \%$ of patients in the rituximab arm and $73.1 \%$ in the placebo arm..$^{52}$

Patel and colleagues studied the durability of response to rituximab over an extended observation period in 189 adults with ITP. The response (platelet count $\geq 50 \times 10^{9} / \mathrm{L}$ ) rate at 1 , 2 , and 5 years after treatment was 38,31 , and $21 \%$, respectively. Strength of initial platelet response and prolonged B cell depletion were predictors of sustained response..$^{53}$

Controlled trials are needed to determine whether the longterm responses observed by Patel et al are attributable to rituximab or whether they merely identify a subset of patients with self-limited disease. More data are also needed in newly diagnosed patients to determine whether rituximab improves the course of disease in this population.

\section{Thrombopoietin Receptor Agonists}

Two TPO-RAs are licensed for the treatment of ITP. Romiplostim is a peptibody that binds to the extracellular domain of the thrombopoietin receptor. Eltrombopag is an oral nonpeptide small molecule that interacts with the receptor's transmembrane domain. Both drugs increase thrombopoiesis by stimulating proliferation and differentiation of platelet progenitors.

TPO-RAs are generally thought not to induce remission. Most patients in the long-term extension studies of romiplostim and eltrombopag required persistent treatment to maintain a platelet count response. Discontinuation or interruption of therapy was associated with a fall in platelet count, which was sometimes severe. ${ }^{54,55}$

However, emerging data suggest that a small percentage of patients may experience a response that persists after discontinuation of TPO-RA ( - Table 4). In the romiplostim extension study, 9 of 292 (3.1\%) patients maintained a platelet count of $>50 \times 10^{9} / \mathrm{L}$ for at least 6 months after discontinuation of romiplostim. These patients had ITP for a variable period before treatment $(0.1-5.5$ years $)$ and variable exposure to romiplostim ( 8.5 months to 2.7 years). All had received at least two previous treatments for ITP. One patient required resumption of romiplostim after 3.2 years off treatment. ${ }^{54}$ No predictors of sustained response off romiplostim were identified. ${ }^{56}$ At least three additional patients from earlier romiplostim trials were able to discontinue romiplostim and maintain a platelet count $>50 \times 10^{9} / \mathrm{L}$ off treatment for 9 months to 4.5 years. ${ }^{57}$ In a single-center Canadian series, 3 of 31 (9.7\%) TPO-RA-treated patients experienced durable remission (platelet count $>100 \times 10^{9}$ / L) after discontinuation of treatment. All three had chronic disease, had received 3 to 5 previous therapies, and remained in remission for 11 to 28 months at the time of last followup. ${ }^{58}$ Seven of $54(13.0 \%)$ patients treated with TPO-RA in a multicenter French study sustained a complete response (platelet count of $>100 \times 10^{9} / \mathrm{L}$ ) 5 to 27 months after

Table 4 Durable platelet count responses after discontinuation of treatment with TPO-RAs in adults with chronic ITP

\begin{tabular}{|l|l|l|l|}
\hline Reference & $\boldsymbol{n}$ & Definition of durable platelet response & Response rate (\%) \\
\hline 54 & 292 & $>50 \times 10^{9} / \mathrm{L}$ off treatment for $\geq 6$ mo & 3.1 \\
\hline 58 & 31 & $>50 \times 10^{9} / \mathrm{L}$ off treatment for $\geq 9$ mo & 9.7 \\
\hline 59 & 54 & $>100 \times 10^{9} / \mathrm{L}$ off treatment for $\geq 5$ mo & 13.0 \\
\hline
\end{tabular}

Abbreviations: ITP, immune thrombocytopenia; TPO-RAs, thrombopoietin receptor agonists. 
Table 5 Platelet count responses at 6-12 months in prospective studies of combination therapy with high-dose dexamethasone and rituximab in adults with previously untreated ITP

\begin{tabular}{|c|c|c|c|c|}
\hline \multirow[t]{2}{*}{ Reference } & \multirow[t]{2}{*}{ Intervention } & \multirow{2}{*}{$\begin{array}{l}\text { Definition of platelet } \\
\text { response }\end{array}$} & \multicolumn{2}{|c|}{ Response rate } \\
\hline & & & $6 \mathrm{mo}$ & $12 \mathrm{mo}$ \\
\hline 61 & $\begin{array}{l}\text { Dex } 40 \mathrm{mg} / \mathrm{d} \text { on days } 1-4 \times 1 \text { cycle and rituximab } 100 \mathrm{mg} \\
\text { on days } 1,8,15,22\end{array}$ & $\geq 100 \times 10^{9} / \mathrm{L}$ & $76 \%$ & - \\
\hline 9 & $\begin{array}{l}\text { Dex } 40 \mathrm{mg} / \mathrm{d} \text { on days } 1-4 \times 1 \text { cycle } \\
\text { Dex } 40 \mathrm{mg} / \mathrm{d} \text { on days } 1-4 \times 1 \text { cycle and rituximab } 375 \\
\mathrm{mg} / \mathrm{m}^{2} \text { on days } 7,14,21,28\end{array}$ & $\geq 50 \times 10^{9} / \mathrm{L}$ & $\begin{array}{l}36 \% \\
63 \%\end{array}$ & $\overline{-}$ \\
\hline 62 & $\begin{array}{l}\text { Dex } 40 \mathrm{mg} / \mathrm{d} \text { on days } 1-4 \times \leq 6 \text { cycles } \\
\text { Dex } 40 \mathrm{mg} / \mathrm{d} \text { on days } 1-4 \times \leq 6 \text { cycles and rituximab } 375 \\
\mathrm{mg} / \mathrm{m}^{2} \text { on days } 2,9,16,23\end{array}$ & $\geq 50 \times 10^{9} / \mathrm{L}$ & $\begin{array}{l}37 \% \\
58 \%\end{array}$ & $\begin{array}{l}33 \% \\
53 \%\end{array}$ \\
\hline
\end{tabular}

Abbreviations: Dex, dexamethasone; ITP, immune thrombocytopenia.

discontinuation of treatment. All the patients had chronic ITP and had received a median of five previous therapies. No predictive factors were identified. ${ }^{59}$

Collectively, these data suggest that a small proportion of patients with chronic ITP may enjoy persistent responses after discontinuing TPO-RA therapy ( - Table 4). Whether the persistent responses observed in these studies are attributable to the TPO-RA itself or merely represent spontaneous remissions is unknown. It is conceivable that the studies may underestimate the potential proportion of patients who could safely stop treatment because discontinuation of TPO-RA may not be considered or attempted in many responding patients. The potential for TPO-RAs to induce remissions in newly diagnosed patients is unstudied and merits investigation. Mechanisms by which TPO-RAs may induce remission are unknown. Restoration of immune tolerance by increasing exposure to platelet antigens and/or improving T-regulatory cell function has been speculated..$^{59,60}$

\section{Multiagent Therapy}

\section{Dexamethasone and Rituximab}

Three prospective studies have tested the hypothesis that combination therapy with high-dose dexamethasone and rituximab may improve long-term outcomes in newly diagnosed patients with ITP (- Table 5). In a single-arm Mexican study, 21 patients were treated with one cycle of high-dose dexamethasone and low-dose rituximab $(100 \mathrm{mg})$ weekly $\times 4$ weeks. A second cycle of high-dose dexamethasone was permitted if the platelet count was $<20 \times 10^{9} / \mathrm{L}$ before day 30 . A complete response (platelet count $\left.\geq 100 \times 10^{9} / \mathrm{L}\right)$ at 6 months was attained in $16(76 \%)$ patients. Freedom from relapse (platelet count $<30 \times 10^{9} / \mathrm{L}$ ) was $84 \%$ at 12 months. ${ }^{61}$ In a multicenter trial from Italy, 103 patients were randomized to a single cycle of high-dose dexamethasone with or without rituximab $375 \mathrm{mg} / \mathrm{m}^{2}$ weekly $\times 4$ weeks. The rate of response (platelet count $\geq 50 \times 10^{9} / \mathrm{L}$ ) at 6 months was significantly greater in the combination therapy $\operatorname{arm}(63$ vs. $36 \%, p=0.004$ ). Patients who were refractory to dexamethasone alone were eligible to receive salvage dexamethasone and rituximab. Among patients who achieved a response at 6 months, the probability of maintaining a response at
30 months was unaffected by the intervention $(77 \%$ in the dexamethasone arm, $69 \%$ in the dexamethasone plus rituximab arm, and $85 \%$ in the salvage arm; $p=0.78) .{ }^{9}$ Similar 6-month response rates were obtained in a Danish trial in which 133 patients were randomized to high-dose dexamethasone with or without standard-dose rituximab. Patients in both arms were permitted to receive up to five supplemental cycles of high-dose dexamethasone. The response (platelet count $\geq 50 \times 10^{9} / \mathrm{L}$ ) rate was significantly greater in the combination therapy arm at 6 months ( 58 vs. $37 \%, p=0.02$ ) and at 1 year (53 vs. $33 \%) .{ }^{62}$ In both randomized controlled trials, there were more grade 3 and 4 adverse events in the combination therapy arms. ${ }^{9,62}$

These data indicate that the combination of rituximab and high-dose dexamethasone augments response rates at 6 and 12 months compared with dexamethasone alone in patients with newly diagnosed ITP ( - Table 5 ). It is unknown whether combination therapy also induces superior response rates compared with rituximab alone because of a paucity of data on rituximab monotherapy in newly diagnosed patients. Longer follow-up is required to determine whether combination therapy leads to cure in an additional proportion of patients compared with either agent alone or merely postpones relapse.

\section{Dexamethasone and Thrombopoietin Receptor Agonists}

A combination of dexamethasone and eltrombopag has been tested in a prospective single-arm study. Twelve Mexican adults with newly diagnosed ITP were treated with a single cycle of dexamethasone $40 \mathrm{mg}$ daily on days 1 to 4 followed by eltrombopag $50 \mathrm{mg}$ daily on days 5 to 32 . A sustained response (platelet count $\geq 30 \times 10^{9} / \mathrm{L}$ ) was observed in 9 (75\%) patients at 6 months and $8(67 \%)$ patients at 12 months. ${ }^{63}$ These preliminary findings require confirmation in a larger controlled study.

\section{Conclusion}

Primary ITP in adults assumes a chronic course in the majority of cases, resulting in potentially profound clinical consequences, including an increased risk of bleeding and diminished 
quality of life. Medical therapy has traditionally been viewed as a means of temporarily raising the platelet count with little or no potential to induce protracted remissions off therapy. However, several recent studies have tested the hypothesis that intensive medical therapy administered early in the disease course may improve the long-term course or even cure ITP. This hypothesis is predicated on putative changes in the autoimmune response over time (-Fig. 1), including expansion of autoreactive clones, affinity maturation, epitope spreading, functional diversification of the autoantibody repertoire, and production of long-lived memory populations, which may render the autoimmune response more resistant to eradication with immunomodulatory therapy.

Interpretation of published evidence on long-term platelet responses after medical therapy in adults with newly diagnosed ITP is hampered by a paucity of information on the natural history and spontaneous remission rates of untreated adults with ITP, differences in patient population and definition of platelet response between studies, and a dearth of prospective long-term follow-up, particularly beyond 1 year.

Approximately 40 to $60 \%$ of patients treated with standarddose prednis(ol)one maintain a platelet response at 6 months (-Tables 1 and 3). ${ }^{32,33,45,46}$ There is no consensus on the optimal dose or duration of treatment. Although prospective data are lacking, retrospective series suggest that response rates fall to 20 to $30 \%$ at 2 to 10 years (- Table 2). ${ }^{10,37-41}$ Single cycles of high-dose dexamethasone alone do not improve response rates at 6 months compared with standard-dose prednis(ol)one (-Table 3). ${ }^{45}$ High-dose dexamethasone, delivered in multiple cycles or in combination with rituximab or prednisolone, improves response rates at 6 and 12 months compared with single cycles of high-dose dexamethasone (-Tables 3 and 5). 9,47,48,61,62 Extended follow-up is needed to determine whether the superior responses at 1 year with these intensive regimens translate to greater cure rates or merely delayed relapse.

Data on long-term outcomes in newly diagnosed patients treated with TPO-RA or rituximab monotherapy are lacking. Platelet count responses persist in approximately 20\% of patients with chronic ITP 5 years after rituximab. ${ }^{53}$ Approximately 5 to $10 \%$ of patients with chronic disease experience prolonged responses after discontinuation of TPO-RA (-Table 4). ${ }^{54,58,59}$ These data are not far off the 20 to $30 \%$ of patients who remain in remission years after treatment with standard-dose prednis(ol)one (- Table 2), ${ }^{10,37-41}$ suggesting that they could represent a subset of patients destined to experience spontaneous improvement in their disease irrespective of therapy rather than bona fide responses to treatment.

In light of the limitations of currently available data, evidence regarding the potential for intensive medical therapy to cure ITP must be considered inconclusive. Appropriately controlled trials that employ consensus definitions of newly diagnosed disease and platelet response ${ }^{2}$ as well as extended follow-up are needed to provide definitive evidence and facilitate comparison between studies.

Risks of intensive combination therapy are also unlikely to be fully appreciated. Combination therapy with high-dose dexamethasone and rituximab was associated with greater toxicity than high-dose dexamethasone alone in randomized controlled trials. ${ }^{9,62}$ The long-term effects of intensive combination therapy on immune surveillance in patients with ITP have not been reported, though there is potential for concern. Rituximab induces protracted impairment in the immune response to polysaccharide vaccines ${ }^{64}$ and serious infections including progressive multifocal leukoencephalopathy have been associated with its use, particularly when combined with other immunomodulatory agents. ${ }^{65}$

Given the uncertainty of incremental benefit compared with standard therapy (i.e., increased likelihood of cure) and the potential harms, we do not believe current evidence supports routine use of intensive medical therapy in newly diagnosed patients outside the context of a clinical trial. However, there is sound biologic rationale and clinical justification to support continued pursuit of well-designed trials in this area.

\section{Disclosures}

A. C. has served as a consultant for Baxter, Bayer, and Genzyme; has served on an advisory board for CSL Behring and Genzyme; and has received research support from Diagnostica Stago and T2 Biosystems. E. L. P. has served as a consultant for Genentech and received an honorarium for speaking from Janssen Pharmaceuticals. D. C. has served as a consultant for Bayer, Bristol-Myers Squibb, Canege, Genzyme, Glaxo SmithKline, Instrumentation Laboratories, Omeros, Rigel, and TrueNorth.

\section{Acknowledgments}

This work was supported, in part, by grants K23 HL112903 (to A.C.), R56 AI 090842 (to E.L.P.), and U34 HL115015 (to D. B.C.) from the National Institutes of Health.

\section{References}

1 Cuker A, Cines DB. Immune thrombocytopenia. Hematology (Am Soc Hematol Educ Program) 2010;2010:377-384

2 Rodeghiero F, Stasi R, Gernsheimer T, et al. Standardization of terminology, definitions and outcome criteria in immune thrombocytopenic purpura of adults and children: report from an international working group. Blood 2009;113(11):2386-2393

3 Donato H, Picón A, Martinez M, et al. Demographic data, natural history, and prognostic factors of idiopathic thrombocytopenic purpura in children: a multicentered study from Argentina. Pediatr Blood Cancer 2009;52(4):491-496

4 Liebman HA, Stasi R. Secondary immune thrombocytopenic purpura. Curr Opin Hematol 2007;14(5):557-573

5 Kojouri K, Vesely SK, Terrell DR, George JN. Splenectomy for adult patients with idiopathic thrombocytopenic purpura: a systematic review to assess long-term platelet count responses, prediction of response, and surgical complications. Blood 2004;104(9):2623-2634

6 Rodeghiero F, Ruggeri M. Short- and long-term risks of splenectomy for benign haematological disorders: should we revisit the indications? Br J Haematol 2012;158(1):16-29

7 Hauber AB, Johnson FR, Grotzinger KM, Ozdemir S. Patients' benefit-risk preferences for chronic idiopathic thrombocytopenic purpura therapies. Ann Pharmacother 2010;44(3):479-488 
8 Bussel JB, Lee CS, Seery C, et al. Rituximab and three dexamethasone cycles provide responses similar to splenectomy in women and those with immune thrombocytopenia of less than two years duration. Haematologica 2014;99(7):1264-1271

9 Zaja F, Baccarani M, Mazza P, et al. Dexamethasone plus rituximab yields higher sustained response rates than dexamethasone monotherapy in adults with primary immune thrombocytopenia. Blood 2010;115(14):2755-2762

10 Stasi R, Stipa E, Masi M, et al. Long-term observation of 208 adults with chronic idiopathic thrombocytopenic purpura. Am J Med 1995;98(5):436-442

11 Sailer T, Lechner K, Panzer S, Kyrle PA, Pabinger I. The course of severe autoimmune thrombocytopenia in patients not undergoing splenectomy. Haematologica 2006;91(8):1041-1045

12 Pizzuto J, Ambriz R. Therapeutic experience on 934 adults with idiopathic thrombocytopenic purpura: Multicentric Trial of the Cooperative Latin American group on Hemostasis and Thrombosis. Blood 1984;64(6):1179-1183

13 McHeyzer-Williams LJ, McHeyzer-Williams MG. Antigen-specific memory B cell development. Annu Rev Immunol 2005;23:487-513

14 Grimaldi D, Canouï-Poitrine F, Croisille L, et al. Antiplatelet antibodies detected by the MAIPA assay in newly diagnosed immune thrombocytopenia are associated with chronic outcome and higher risk of bleeding. Ann Hematol 2014;93(2):309-315

15 McMillan R. The pathogenesis of chronic immune thrombocytopenic purpura. Semin Hematol 2007;44(4, Suppl 5):S3-S11

16 Cines DB, Blanchette VS. Immune thrombocytopenic purpura. N Engl J Med 2002;346(13):995-1008

17 Roark JH, Bussel JB, Cines DB, Siegel DL. Genetic analysis of autoantibodies in idiopathic thrombocytopenic purpura reveals evidence of clonal expansion and somatic mutation. Blood 2002; 100(4):1388-1398

18 Jahn S, Niemann B, Winkler T, Kalden JR, von Baehr R. Expansion of a B-lymphocyte clone producing IgM auto-antibodies encoded by a somatically mutated VHI gene in the spleen of an autoimmune patient. Rheumatol Int 1994;13(5):187-196

19 Shlomchik MJ, Craft JE, Mamula MJ. From T to B and back again: positive feedback in systemic autoimmune disease. Nat Rev Immunol 2001;1(2):147-153

20 Cines DB, Cuker A, Semple JW. Pathogenesis of immune thrombocytopenia. Presse Med 2014;43(4, Pt 2):e49-e59

21 Chang M, Nakagawa PA, Williams SA, et al. Immune thrombocytopenic purpura (ITP) plasma and purified ITP monoclonal autoantibodies inhibit megakaryocytopoiesis in vitro. Blood 2003;102(3):887-895

22 Tsubakio T, Tani P, Curd JG, McMillan R. Complement activation in vitro by antiplatelet antibodies in chronic immune thrombocytopenic purpura. Br J Haematol 1986;63(2):293-300

23 Horikawa K, Martin SW, Pogue SL, et al. Enhancement and suppression of signaling by the conserved tail of IgG memorytype B cell antigen receptors. J Exp Med 2007;204(4):759-769

24 Martin SW, Goodnow CC. Burst-enhancing role of the IgG membrane tail as a molecular determinant of memory. Nat Immunol 2002;3(2):182-188

25 Leandro MJ. B-cell subpopulations in humans and their differential susceptibility to depletion with anti-CD20 monoclonal antibodies. Arthritis Res Ther 2013;15(Suppl 1):S3

26 Eisenberg RA, Jawad AF, Boyer J, et al. Rituximab-treated patients have a poor response to influenza vaccination. J Clin Immunol 2013;33(2):388-396

27 Mahévas M, Patin P, Huetz F, et al. B cell depletion in immune thrombocytopenia reveals splenic long-lived plasma cells. J Clin Invest 2013;123(1):432-442

28 Liu YJ, Barthélémy C, de Bouteiller O, Arpin C, Durand I, Banchereau $\mathrm{J}$. Memory B cells from human tonsils colonize mucosal epithelium and directly present antigen to T cells by rapid up-regulation of B71 and B7-2. Immunity 1995;2(3):239-248

29 Kindler V, Zubler RH. Memory, but not naive, peripheral blood B lymphocytes differentiate into Ig-secreting cells after CD40 liga- tion and costimulation with IL- 4 and the differentiation factors IL2, IL-10, and IL-3. J Immunol 1997;159(5):2085-2090

30 Tangye SG, Avery DT, Hodgkin PD. A division-linked mechanism for the rapid generation of Ig-secreting cells from human memory B cells. J Immunol 2003;170(1):261-269

31 Tangye SG, Liu YJ, Aversa G, Phillips JH, de Vries JE. Identification of functional human splenic memory B cells by expression of CD148 and CD27. J Exp Med 1998;188(9):1691-1703

32 Mazzucconi MG, Francesconi M, Fidani P, et al. Treatment of idiopathic thrombocytopenic purpura (ITP): results of a multicentric protocol. Haematologica 1985;70(4):329-336

33 Bellucci S, Charpak Y, Chastang C, Tobelem G. Low doses v conventional doses of corticoids in immune thrombocytopenic purpura (ITP): results of a randomized clinical trial in 160 children, 223 adults. Blood 1988;71(4):1165-1169

34 Godeau B, Chevret S, Varet B, et al; French ATIP Study Group. Intravenous immunoglobulin or high-dose methylprednisolone, with or without oral prednisone, for adults with untreated severe autoimmune thrombocytopenic purpura: a randomised, multicentre trial. Lancet 2002;359(9300):23-29

35 Newman GC, Novoa MV, Fodero EM, Lesser ML, Woloski BM, Bussel JB. A dose of $75 \mathrm{microg} / \mathrm{kg} / \mathrm{d}$ of i.v. anti-D increases the platelet count more rapidly and for a longer period of time than 50 microg/ $\mathrm{kg} / \mathrm{d}$ in adults with immune thrombocytopenic purpura. $\mathrm{Br} \mathrm{J}$ Haematol 2001;112(4):1076-1078

36 Cooper N, Woloski BM, Fodero EM, et al. Does treatment with intermittent infusions of intravenous anti-D allow a proportion of adults with recently diagnosed immune thrombocytopenic purpura to avoid splenectomy? Blood 2002;99(6):1922-1927

37 Thompson RL, Moore RA, Hess CE, Wheby MS, Leavell BS. Idiopathic thrombocytopenic purpura. Long-term results of treatment and the prognostic significance of response to corticosteroids. Arch Intern Med 1972;130(5):730-734

38 DiFino SM, Lachant NA, Kirshner JJ, Gottlieb AJ. Adult idiopathic thrombocytopenic purpura. Clinical findings and response to therapy. Am J Med 1980;69(3):430-442

39 Portielje JE, Westendorp RG, Kluin-Nelemans HC, Brand A. Morbidity and mortality in adults with idiopathic thrombocytopenic purpura. Blood 2001;97(9):2549-2554

40 Leung AY, Chim CS, Kwong YL, Lie AK, Au WY, Liang R. Clinicopathologic and prognostic features of chronic idiopathic thrombocytopenic purpura in adult Chinese patients: an analysis of 220 cases. Ann Hematol 2001;80(7):384-386

41 Pamuk GE, Pamuk ON, Başlar Z, et al. Overview of 321 patients with idiopathic thrombocytopenic purpura. Retrospective analysis of the clinical features and response to therapy. Ann Hematol 2002;81(8):436-440

42 McMillan R, Durette C. Long-term outcomes in adults with chronic ITP after splenectomy failure. Blood 2004;104(4):956-960

43 Neylon AJ, Saunders PW, Howard MR, Proctor SJ, Taylor PR; ; Northern Region Haematology Group. Clinically significant newly presenting autoimmune thrombocytopenic purpura in adults: a prospective study of a population-based cohort of 245 patients. $\mathrm{Br}$ J Haematol 2003;122(6):966-974

44 Cheng Y, Wong RS, Soo YO, et al. Initial treatment of immune thrombocytopenic purpura with high-dose dexamethasone. N Engl J Med 2003;349(9):831-836

45 Bae SH, Ryoo HM, Lee WS, et al. High dose dexamethasone vs. conventional dose prednisolone for adults with immune thrombocytopenia: a prospective multicenter phase III trial. Paper presented at: Annual Meeting of the American Society of Hematology; December 2010; Orlando, FL

46 Mashhadi MA, Kaykhaei MA, Sepehri Z, Miri-Moghaddam E. Single course of high dose dexamethasone is more effective than conventional prednisolone therapy in the treatment of primary newly diagnosed immune thrombocytopenia. Daru 2012;20(1):7

47 Borst F, Keuning JJ, van Hulsteijn H, Sinnige H, Vreugdenhil G. Highdose dexamethasone as a first- and second-line treatment of 
idiopathic thrombocytopenic purpura in adults. Ann Hematol 2004;83(12):764-768

48 Mazzucconi MG, Fazi P, Bernasconi S, et al; Gruppo Italiano Malattie EMatologiche dell'Adulto (GIMEMA) Thrombocytopenia Working Party. Therapy with high-dose dexamethasone (HDDXM) in previously untreated patients affected by idiopathic thrombocytopenic purpura: a GIMEMA experience. Blood 2007; 109(4):1401-1407

49 Zaja F, Vianelli N, Volpetti S, et al. Low-dose rituximab in adult patients with primary immune thrombocytopenia. Eur J Haematol 2010;85(4):329-334

50 Arnold DM, Dentali F, Crowther MA, et al. Systematic review: efficacy and safety of rituximab for adults with idiopathic thrombocytopenic purpura. Ann Intern Med 2007;146(1):25-33

51 Auger S, Duny Y, Rossi JF, Quittet P. Rituximab before splenectomy in adults with primary idiopathic thrombocytopenic purpura: a meta-analysis. Br J Haematol 2012;158(3):386-398

52 Arnold DM, Heddle NM, Carruthers J, et al. A pilot randomized trial of adjuvant rituximab or placebo for nonsplenectomized patients with immune thrombocytopenia. Blood 2012;119(6):1356-1362

53 Patel VL, Mahévas M, Lee SY, et al. Outcomes 5 years after response to rituximab therapy in children and adults with immune thrombocytopenia. Blood 2012;119(25):5989-5995

54 Kuter DJ, Bussel JB, Newland A, et al. Long-term treatment with romiplostim in patients with chronic immune thrombocytopenia: safety and efficacy. Br J Haematol 2013;161(3):411-423

55 Saleh MN, Bussel JB, Cheng G, et al; EXTEND Study Group. Safety and efficacy of eltrombopag for treatment of chronic immune thrombocytopenia: results of the long-term, open-label EXTEND study. Blood 2013;121(3):537-545

56 Bussel JB, Rodeghiero F, Lyons RM, et al. Sustained hemostatic platelet counts in adults with immune thrombocytopenia (ITP) following cessation of treatment with the TPO receptor agonist romiplostim: report of 9 cases. Paper presented at: Annual Meeting of the American Society of Hematology; December 6, 2011; San Diego, CA
57 Newland A, Cervinek L, Eggermann J, Lefrere F, Kreutzbauer G. Sustained hemostatic platelet counts in adult patients with primary immune thrombocytopenia (ITP) following cessation of romiplostim-four European case studies. Paper presented at: Annual Meeting of the European Society of Hematology; June 2011; London, United Kingdom

58 Ghadaki B, Nazi I, Kelton JG, Arnold DM. Sustained remissions of immune thrombocytopenia associated with the use of thrombopoietin receptor agonists. Transfusion 2013;53(11):2807-2812

59 Mahévas M, Fain O, Ebbo M, et al. The temporary use of thrombopoietin-receptor agonists may induce a prolonged remission in adult chronic immune thrombocytopenia. Results of a French observational study. Br J Haematol 2014;165(6):865-869

60 Bao W, Bussel JB, Heck S, et al. Improved regulatory T-cell activity in patients with chronic immune thrombocytopenia treated with thrombopoietic agents. Blood 2010;116(22):4639-4645

61 Gómez-Almaguer D, Tarín-Arzaga L, Moreno-Jaime B, et al. High response rate to low-dose rituximab plus high-dose dexamethasone as frontline therapy in adult patients with primary immune thrombocytopenia. Eur J Haematol 2013;90(6):494-500

62 Gudbrandsdottir S, Birgens HS, Frederiksen H, et al. Rituximab and dexamethasone vs dexamethasone monotherapy in newly diagnosed patients with primary immune thrombocytopenia. Blood 2013;121(11):1976-1981

63 Gómez-Almaguer D, Herrera-Rojas MA, Jaime-Pérez JC, et al. Eltrombopag and high-dose dexamethasone as frontline treatment of newly diagnosed immune thrombocytopenia in adults. Blood 2014;123(25):3906-3908

64 Nazi I, Kelton JG, Larché M, et al. The effect of rituximab on vaccine responses in patients with immune thrombocytopenia. Blood 2013;122(11):1946-1953

65 Carson KR, Evens AM, Richey EA, et al. Progressive multifocal leukoencephalopathy after rituximab therapy in HIV-negative patients: a report of 57 cases from the Research on Adverse Drug Events and Reports project. Blood 2009;113(20):4834-4840 